Сидорова Наталья Васильевна

кандидат социологических наук, доцент кафедры социологии и психологии Иркутского национального исследовательского технического университета

\section{СОЦИАЛЬНО-ЭКОЛОГИЧЕСКИЕ ПРОБЛЕМЫ ПРИБАЙКАЛЬЯ: АНАЛИЗ ОБЩЕСТВЕННОГО МНЕНИЯ ЖИТЕЛЕЙ ОСТРОВА ОЛЬХОН}

Аннотация:

В статье рассматривается отношение местных жителей к социально-экологическим проблемам Прибайкалья. Остров Ольхон входит в чентральную экологическую и водоохранную зоны озера Байкал, что предполагает запрет на развитие промышленности и производства, делая Ольхон высокодотационным районом. Такая социально-экономическая ситуация стимулирует в нетуристический сезон отток местного населения на заработки в другие регионы, усиливает с его стороны негативный настрой с требованиями снять ограничения и запреты. В статье отражены результаты исследования отношения местного населения к деятельности Прибайкальского национального парка как государственной организации, к увеличению туристического потока. Приводятся результаты социологических опросов, выявивиих $в$ Прибайкалье две многочисленные устойчивые группы респондентов, которые являются носителями диаметрально противоположных мнений о туристах на острове Ольхон. Мнение этих групп нельзя не учитывать при формировании туристической политики Прибайкалья.

Ключевые слова:

национальный парк, туристический поток, факторы привлекательности территории, туристы.
Sidorova Natalia Vasilyevna

PhD in Social Science, Associate Professor, Sociology and Psychology Department, Irkutsk National Research Technical University

\section{SOCIAL AND ECOLOGICAL PROBLEMS OF THE BAIKAL REGION: ANALYSIS OF PUBLIC OPINION OF OLKHON ISLAND RESIDENTS}

Summary:

The study deals with the social and ecological problems of the Baikal region and the attitude of local residents towards them. Olkhon Island is a part of the central environmental and water protection zone of Lake Baikal, which implies a ban on the industrial and production development, making the island a heavily subsidized district. This social and economic situation stimulates the outflow of local population in order to work in other regions in non-peak season and increases the negative mood of residents followed by their requirements to remove restrictions and prohibitions. The research analyzes the attitude of local people towards the Pribaikalsky National Park as a state organization and the tourist arrivals in this regard. The sociological surveys revealed two groups of respondents with the contrary opinions on the increasing tourist flow to Olkhon Island. The views of these groups should be taken into account when developing tourism policy in the Baikal region.

Остров Ольхон на Байкале является одним из самых притягательных мест для туристов и гостей не только на территории Прибайкалья, но и в целом в России. С одной стороны - он притягивает огромным количеством солнечных дней, просторами и пляжами, с другой - сакральностью самого своего местонахождения. Местным жителям и администрации на недостаток туристов жаловаться не приходится, но экологи бьют тревогу и требуют введения огромного количества запретов на посещение острова Ольхон. Со стороны государства и, как следствие, сотрудников национального парка вводятся ограничения и ужесточение действий в отношении туристов и местного населения. Данный факт вызывает со стороны последних явное недовольство и даже противодействие [1]. Результаты исследования позволяют анализировать эффективность деятельности администрации национального парка в целом, так как ей необходимо выстраивать системную политику взаимодействия с местным населением [2; 3].

В феврале - апреле 2017 г. сотрудниками и студентами кафедры социологии и социальной работы ФГБОУ ВО «Иркутский национальный исследовательский технический университет» (ИРНИТУ) при поддержке дирекции и сотрудников ФГБУ «Заповедное Прибайкалье» был проведен опрос в поселке Хужир (о. Ольхон). Цель опроса - выяснить отношение жителей поселка к деятельности Прибайкальского национального парка, входящего в ФГБУ «Заповедное Прибайкалье».

Обоснование выборочной совокупности. Выборка является многоступенчатой, случайной с элементами неслучайного отбора. В качестве ступеней отбора выступают: 1) районированный (кластерный) отбор. Для расчета объема выборочной совокупности использовался пропорциональный отбор с нормированной процентной ставкой 5 \% (генеральная совокупность составляет $\mathrm{N}=1668$ человек); 2) внутри кластера - квотный отбор с учетом половозрастных признаков 
населения, основан на данных Иркутскстата. В качестве квот выступили данные по полу и возрасту респондентов (таблица 1).

Таблица 1 - Модель выборочной совокупности сельского населения для Ольхонского муниципального района (о. Ольхон), \%

\begin{tabular}{|l|c|c|c|}
\hline \multicolumn{1}{|c|}{ Возраст } & Мужчины & Женщины & Итого \\
\hline 18-34 года & 17 & 14 & 31 \\
\hline 35-54 года & 18 & 18 & 36 \\
\hline 55 лет и старше & 14 & 19 & 33 \\
\hline Итого & 49 & 51 & 100 \\
\hline
\end{tabular}

Описание социально-демографических характеристик выборочной совокупности. Методом полуструктурированного интервью в поселке Хужир было опрошено 104 человека, из них 49 мужчин и 55 женщин. В возрастной группе от 18 до 34 лет было опрошено 16,3 \% мужчин и 15,4 \% женщин, в группе от 35 до 54 лет - 17,3 \% мужчин, 19,2 \% женщин, в возрасте 55 лет и старше опрошено 13,5 \% мужчин и 18,3 \% женщин (рисунок 1).

Большая часть опрошенных имеют среднее специальное $(36,5 \%)$ и высшее $(32,7 \%)$ образование, у 18,3 \% - полное среднее, у 11,5 \% - неполное среднее. На вопрос об уровне доходов наиболее распространенный ответ был «хватает на необходимое» (43,3\%), оценили свой доход как средний 35,6 \% опрошенных, выше среднего - 9,6 \%, за чертой бедности находятся 9,6 \%.

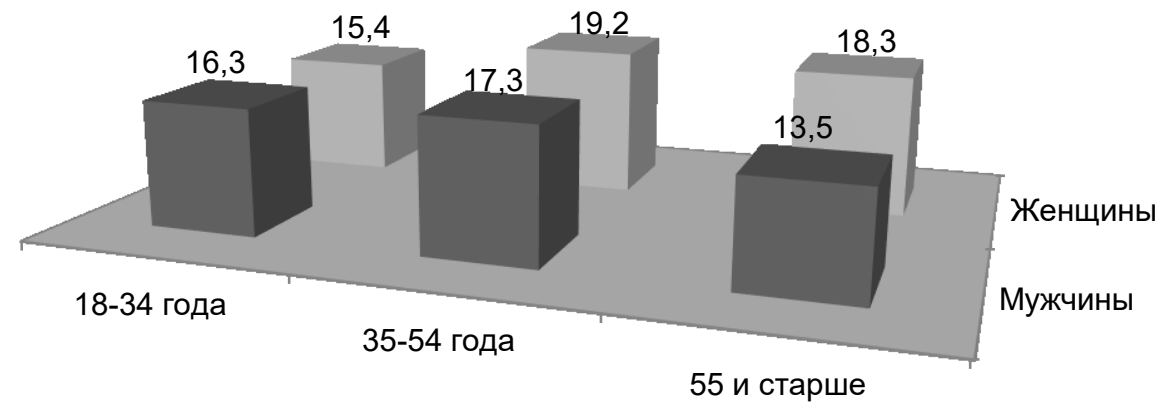

Рисунок 1 - Половозрастной состав выборочной совокупности в поселке Хужир (социально-демографические показатели), \%

Пенсионеров среди опрошенных - 23 \%, работников бюджетной сферы - 12,5, предпринимателей - 11,5, госслужащих - 5,8, учащихся - 3, работающих по найму - 7,7, безработных 21,2, фрермеров - 4,8, работающих в туристическом бизнесе - 3,8 \%.

Современные исследования показывают, что на восприятие территории местными жителями и туристами влияет множество факторов, в том числе привлекательности, скученности и удовлетворенности [4]. Эти фракторы были проанализированы и в ходе нашего исследования.

В ходе интервьюирования респондентов был актуализирован блок вопросов, касающихся привлекательности острова Ольхон для туристического посещения. Так, на вопрос: «Как Вы считаете, что привлекает туристов при посещении Прибайкальского национального парка и конкретно Вашего поселения?» - были получены следующие ответы. Безоговорочным лидером стал вариант - «красоты природы» - 84,6 \% респондентов, что вполне логично, ведь красота Байкала в целом и острова Ольхон в частности известна не только в России, но и далеко за ее пределами. Более того, необходимо было выяснить, какие конкретно места и достопримечательности Ольхона, по мнению местного населения, популярны у приезжающих. Местные достопримечательности в целостном их восприятии привлекают туристов - так считает 12,5 \% опрошенных. Детализируя, респонденты называют само озеро Байкал - 1 \%, скалу Шаманку - 6,7, мыс Хобой - 3,8 и мыс Бурхан - 1,9\%, т. е. основные экскурсионные маршруты, по которым местные возят туристов. Также были отмечены «вкусная местная кухня» и «удобные гостиницы» $(7,7 \%)$, причем упор делался скорее на этническую кухню, в частности на знаменитые бурятские позы. 4,8 \% набрал такой фрактор привлекательности, как «доступность». Показатель доступности острова выглядит достаточно условно, учитывая специфику парома и ледяных переправ, а также рассматривая доступность в свете многочисленных жалоб туристов на отсутствие парковок для личного транспорта, многокилометровые очереди и конфликты с местными жителями в подобных очередях. «Интересные проекты и мероприятия», реализуемые сотрудниками парка, считает привлекательными для туристов лишь 1 \% респондентов. «Поселение и сам парк» совершенно непривлекательны для туристов, так считают $1 \%$. И, наконец, не дал ответа $1 \%$ опрошенных (рисунок 2 ). 


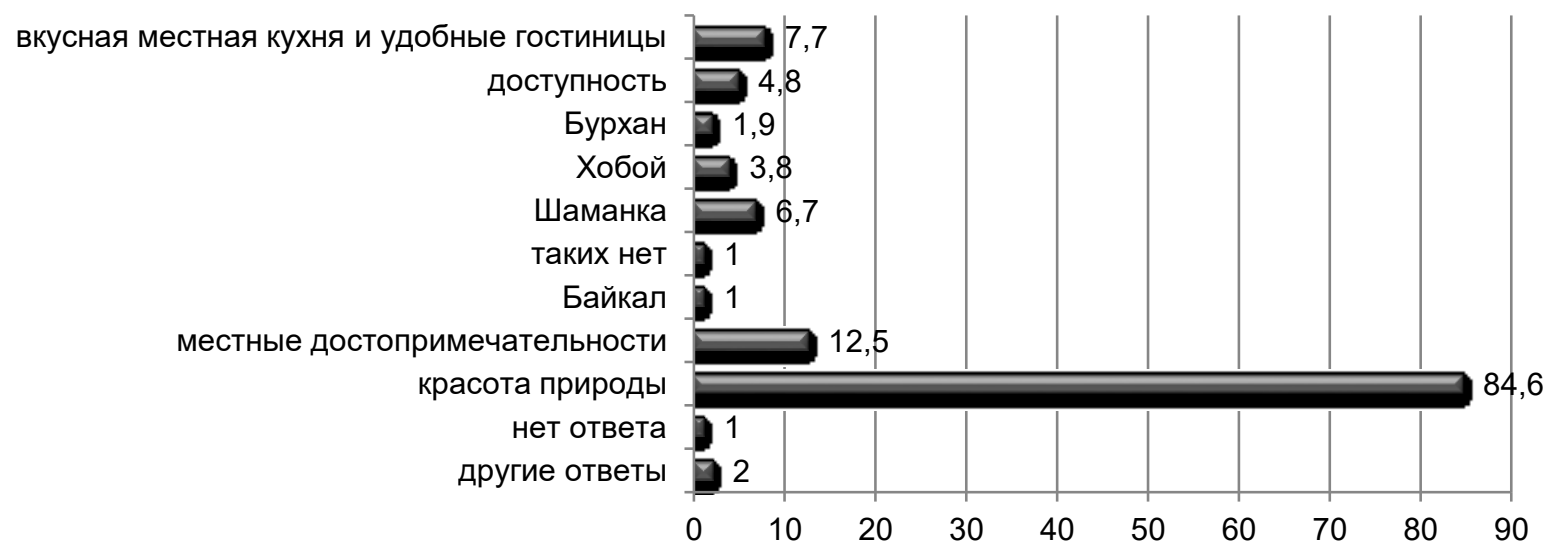

Рисунок 2 - Факторы привлекательности острова Ольхон для посещения туристами, \%

Следующий вопрос касался отношения местного населения к туристам и был сформулирован следующим образом: «Как Вы относитесь к увеличению туристического потока в целом и к туристам в частности?» С одной стороны, 47,1 \% опрошенных ответили, что относятся положительно, так как туристы - это источник дохода для местного населения; 14,4 \% также отметили, что благодаря туристам власти начнут вкладывать деньги в развитие поселений; 2,9 \% высказались, что туристы помогают благоустраивать и очищать от мусора территорию национального парка. С другой стороны, 21,2 \% высказались в отношении туристов отрицательно, потому что туристы загрязняют природу парка, нарушают баланс; к ним присоединились 5,8 \% респондентов, которые посчитали, что туристы мешают спокойно жить местному населению. Таким образом, мнения разделились: есть те, кто вполне благожелательно относится к туристам, и те, кто винит туристов во всех своих проблемах. 8,7 \% жителей выразили полное равнодушие к приезжающим туристам, так как дел с ними они не имеют (рисунок 3 ).

Отрицательно, потому что туристы загрязняют природу парка, нарушают баланс

Отрицательно, они мешают спокойно жить местному населению

Нейтрально, мне все равно, я с туристами не имею дела

Положительно, туристы помогают

благоустраивать и очищать от мусора территорию национального парка

Положительно, туристы - это источник дохода для местного населения

Положительно, власти начнут вкладывать деньги в развитие поселений

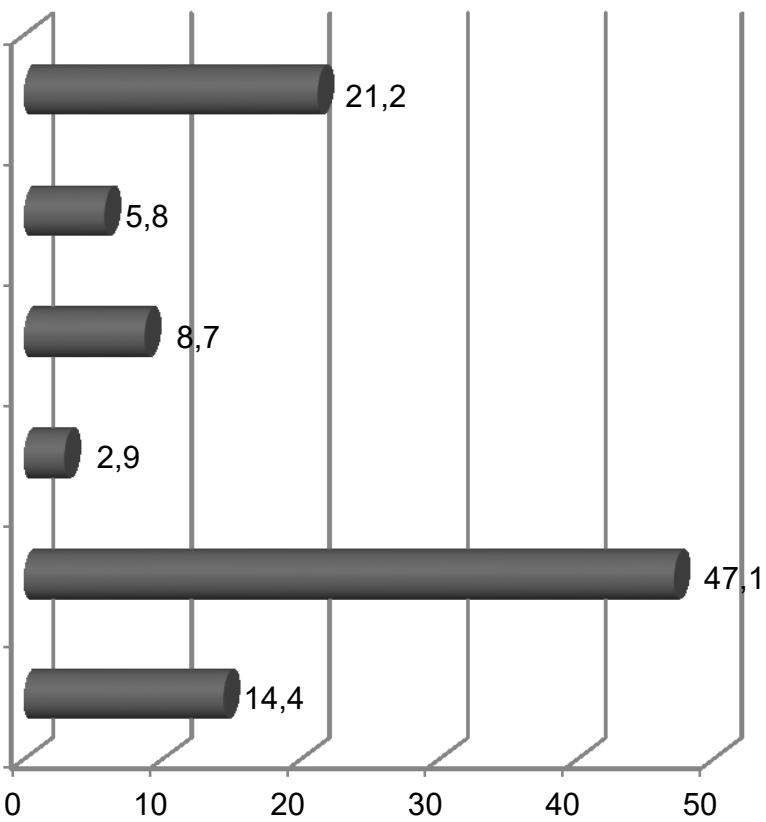

Рисунок 3 - Отношение населения поселка Хужир к увеличению туристического потока, \%

Но в свете существующего тренда и наличия огромного количества программ по привлечению туристов, невзирая на достаточно враждебный настрой местных жителей, был задан вопрос о возможностях привлечения туристов на о. Ольхон. 51 \% респондентов считают, что для этого нужно развивать инфраструктуру (прокладывать удобные тропы и дороги, проводить освещение, выделять субсидии местному населению на открытие своего бизнеса - строительство кемпингов, производство сувенирной продукции, сельхозпроизводство с целью продажи туристам фермерской экопродукции). Совершенно противоположное мнение высказали 32,7 \% опрошенных. Они считают, что привлекать туристов не нужно, их и так слишком много. 
Итак, при опросе населения четко выделились две многочисленные устойчивые группы респондентов, являющихся носителями противоположных точек зрения. Такая тенденция отражается в отчетах практически по всем вопросам исследования.

Немногочисленными были предложения по улучшению работы: «увеличить инфрормационное освещение богатств национального парка в СМИ разного уровня» считают необходимым 5,8 \% опрошенных жителей поселка Хужир, что коррелирует с ситуацией низкой информированности населения относительно деятельности парка; «привлекать туристов, в первую очередь школьников и молодежь, с помощью различных волонтерских проектов» - 9,6 \% респондентов, хотя проектов уже достаточно, но опять же встает вопрос о низкой информированности относительно них; «чтобы туристы просто приезжали посмотреть достопримечательности» - 3,8 \% ответивших; также было высказано замечание: «нужно равномерно распределять поток туристов по месяцам» - 1 \% и затруднился ответить 1 \% принимавших участие в опросе (рисунок 4).

нужно равномерно распределять поток туристов по месяцам

чтобы туристы просто приезжали посмотреть достопримечательности

привлекать туристов не нужно, их и так слишком много

привлекать туристов, в первую очередь школьников и молодежь, с помощью различных волонтерских проектов

увеличить информационное освещение богатства национального парка в СМИ разного уровня

развивать инфраструктуру (прокладывать удобные тропы и дороги, проводить освещение, выделять субсидии местному населению на открытие своего бизнеса - кемпингов, производство сувенирной продукции, сельхозпроизводство с целью продажи туристам фермерской экопродукции)

затрудняюсь ответить, не знаю, нет ответа

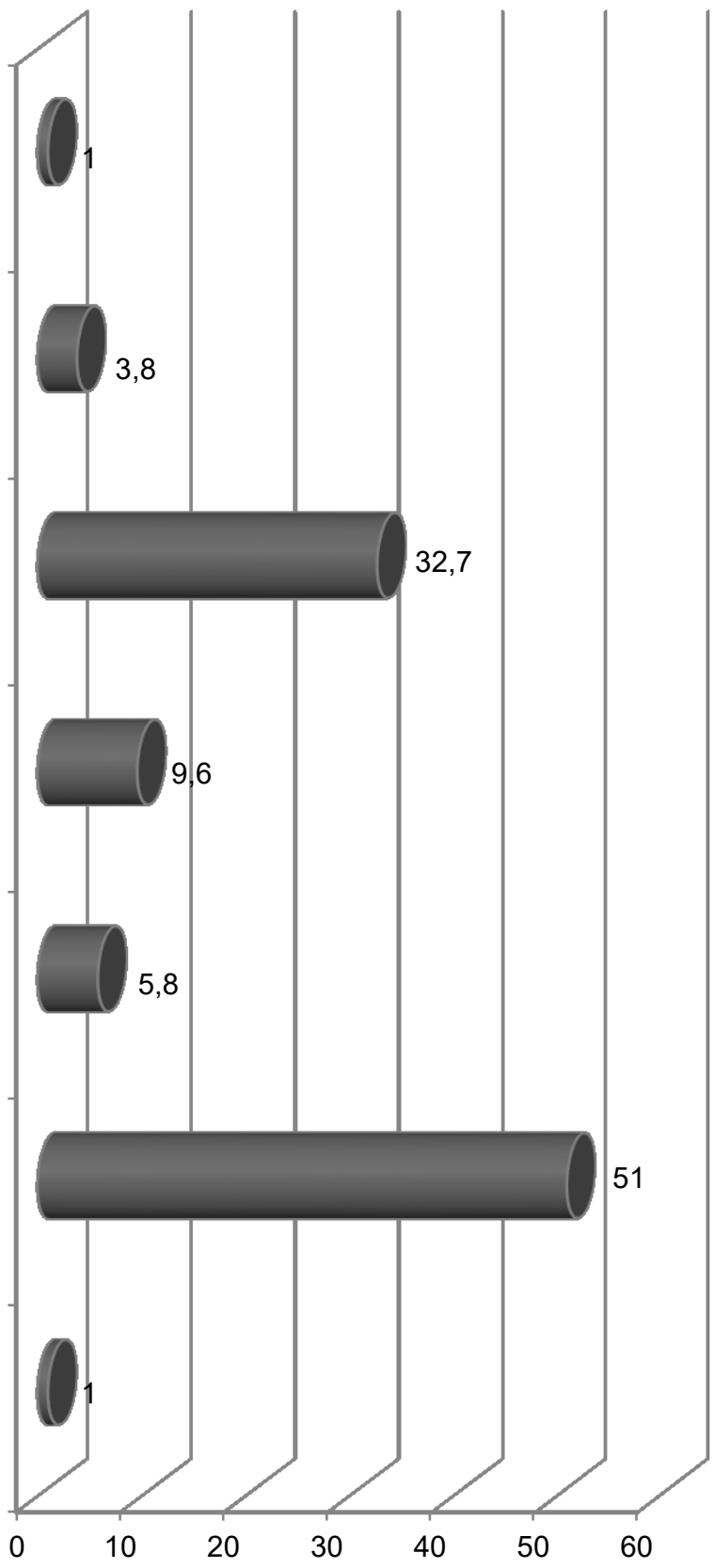

Рисунок 4 - Мероприятия по привлечению туристов на территорию Прибайкальского национального парка и конкретно в поселения острова Ольхон (\%) 
Хотя некоторые ответы на предыдущие вопросы выявили, что среди опрошенных представителей местного населения существует группа людей, не имеющих никакого отношения к туристам и туристическому бизнесу, в связи со спецификой опроса и поставленными задачами был задан отдельный вопрос: «Как конкретно Вы и Ваша семья работают с приезжающими в Ваше поселение туристами?». 48,1 \% ответили: «Никак не работаю, мне это не нужно», т. е. они в принципе не намерены даже в будущем начинать работать с туристами. 4,8 \% респондентов вообще были категоричны, ответив, что туристов на нашей территории быть не должно.

От тех, кто собирается или уже работает с туристами, были получены следующие варианты ответов: «предоставляю услуги проживания, бани» - 32,7 \%; «организую пешие, конные экскурсии, рыбалку» - 18,3; «изготавливаю и реализую сувенирную продукцию» - 1,9; «у меня кафе» - 4,8; «работаю продавцом», «сотрудник кафе» - 1 \%. Эти цифры говорят о том, что доход достаточно большой части населения острова Ольхон зависит от успешности туристического бизнеса (рисунок 5). никак не работаю, мне это не нужно;

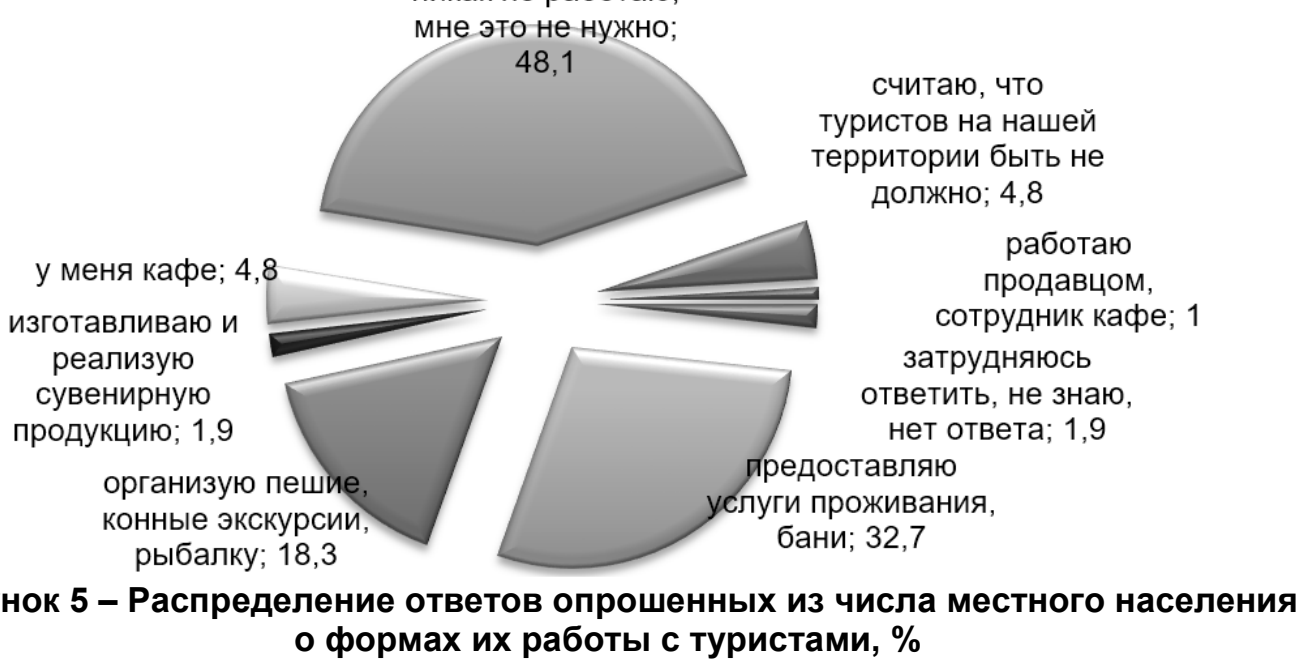

Выводы. Настоящее исследование посвящено анализу многочисленных проблем Прибайкальского региона, в частности особое внимание авторы исследования уделили отношению жителей острова Ольхон к проблеме возрастающего туристического потока.

Являясь частью более масштабного регионального исследования, оно продемонстрировало общую корреляцию с проблемами всего Прибайкалья, при этом отражая и собственные территориальные и социально-экономические проблемы [5, с. 54].

Так, в части отношения к туристам почти половина из опрошенных местных жителей положительно относится к увеличению туристического потока, так как живет на доходы, полученные с туристического бизнеса. Они считают, что нужно принять ряд дополнительных мер по привлечению туристов на о. Ольхон. Треть опрошенных местных жителей видят в туристах - доход от которых получают только крупные турбазы и национальный парк - не заработок и не способ развития острова за счет федеральных вливаний в турсферу, а источник проблемы бытовых отходов. Особенно острая ситуация с туристами из Китая, поток которых за последние два-три года увеличился даже не в десятки, а в сотни раз. В связи с этим местные жители высказывали в интервью опасения по поводу сохранения природы и чистоты острова. В ходе анализа полученных данных явно определились две многочисленные группы респондентов, которые являются носителями диаметрально противоположных мнений по отношению к туристам. И мнение этих групп нельзя не учитывать при формировании туристической политики Прибайкалья.

\section{Ссылки:}

1. Виноградов Е.С. Проблемы развития экологического туризма на особо охраняемых природных территориях России // Теория и практика сервиса: экономика, социальная сфера, технологии. 2014. № 4 (22). С. 118-123.

2. Макарова К.А. Проблемы организации новых национальных парков в России и оценка эффективного развития экологического туризма на их территории // Вестник Тамбовского университета. 2013. Т. 18, вып. 2. С. 651-654.

3. Обоснование и перспективы интеграции естественно-научных и социологических исследований в районах экологического стресса при выбросах дурнопахнущих легколетучих органических соединений для управления качеством воздуха Байкальского региона / Е.Н. Струк, Н.И. Янченко, В.Л. Рупосов, А.М. Янченко // Современное состояние и перспективы улучшения экологии и безопасности жизнедеятельности Байкальского региона «Белые ночи - 2016» : сборник статей Международной научно-технической конференции : в 2 т. Иркутск, 2016. С. 198-203.

4. Tourists' perceptions of crowding, attractiveness, and satisfaction: a second-order structural model / L. Li, J. Zhang, S. Nian, H. Zhang // Asia Pacific Journal of Tourism Research. 2017. Vol. 22, no. 12. P. 1250-1260.

5. Гузик М.В., Сидорова Н.В., Струк Е.Н. Исследование отношения жителей Иркутского муниципального района к деятельности ФГБУ «Заповедное Прибайкалье» // Социальная компетентность. 2017. № 2. С. 54-60. 


\section{References:}

Guzik, MV, Sidorova, NV \& Struk, EN 2017, 'Studying the attitude of the Irkutsk municipal district residents to the Reserved Baikal region activities', Sotsial'naya kompetentnost', no. 2, pp. 54-60, (in Russian).

Li, L, Zhang, J, Nian, S \& Zhang, H 2017, 'Tourists' perceptions of crowding, attractiveness, and satisfaction: a second-order structural model', Asia Pacific Journal of Tourism Research, vol. 22, no. 12, pp. 1250-1260. https://doi.org/10.1080/10941665.2017.1391305.

Makarova, KA 2013, 'Problems of new national parks arrangement in Russia and the assessment of eco-tourism performance on their territory,' Vestnik Tambovskogo universiteta, vol. 18, iss. 2, pp. 651-654, (in Russian).

Struk, EN, Yanchenko, NI, Ruposov, LV \& Yanchenko, AM 2016, 'Justification and prospects for the integration of natural science and sociological studies in areas of environmental stress in the release of foul-smelling, volatile organic compounds for air quality management in the Baikal region', Sovremennoye sostoyaniye $i$ perspektivy uluchsheniya ekologii $i$ bezopasnosti zhiznedeyatel'nosti Baykal'skogo regiona "Belyye nochi - 2016": sbornik statey Mezhdunarodnoy nauchno-tekhnicheskoy konferentsii, in 2 vols., Irkutsk, pp. 198-203, (in Russian).

Vinogradov, ES 2014, 'Development problems of ecotourism in designated conservation areas of Russia', Teoriya i praktika servisa: ekonomika, sotsial'naya sfera, tekhnologii, no. 4 (22), pp. 118-123, (in Russian). 